\title{
Wireless Moisture Sensor Using a Microstrip Antenna
}

\author{
Tatsuo Toba and Akio Kitagawa \\ Division of Electrical Engineering and Computer Science, Kanazawa University, Kakuma-machi, Kanazawa 920-1192, Japan \\ Correspondence should be addressed to Akio Kitagawa, kitagawa@is.t.kanazawa-u.ac.jp
}

Received 1 May 2011; Revised 21 September 2011; Accepted 23 September 2011

Academic Editor: P. Siciliano

Copyright ( $(2011$ T. Toba and A. Kitagawa. This is an open access article distributed under the Creative Commons Attribution License, which permits unrestricted use, distribution, and reproduction in any medium, provided the original work is properly cited.

\begin{abstract}
A wireless moisture sensor has been developed on the basis of the backscatter characteristic of the microstrip antenna, which works in the far field without a battery. This study aims to develop a wireless sensor with a long communication distance and to apply the wireless applications, such as monitoring the moisture in the wrapped products and surface adsorption of hydrogen peroxide in the biological isolation systems. The dropwise addition of the distilled water on the cleaning tissue is clearly detected by the measurement of the backscattered power from the sensor at the frequencies of $0.954 \mathrm{GHz}$ and $2.45 \mathrm{GHz}$. The ratio of the backscattered power in two frequency bands can be used as an index to measure moisture.
\end{abstract}

\section{Introduction}

Water content, or moisture content, is often used to assess the quality of a product and its optimum handling and processing conditions. Microwave sensors emerged as effective tools for real-time, nondestructive, and continuous sensing of moisture content in a variety of materials [1-4]. The basic idea of the microwave moisture sensors is to measure the dielectric constant in a composite material such as the soil, foodstuffs, and building structures, which have permittivity that is mainly governed by the presence of liquid water $[3,4]$. Some principles of the dielectric measurement have been proposed, for example, the time-domain reflectometry (TDR) [5], the microstrip resonator [6], and the phase shift detection of the transmission line [4] or parallel-plate electrode [7]. In these conventional measurements, the materials under test conditions must be brought into contact with the free face of microstripline or put in the near-field region of the probing electrodes. Therefore, the conventional methods are difficult to apply to the wireless applications in the far field, such as monitoring the moisture in the wrapped food and surface adsorption of hydrogen peroxide in the biological isolation systems.

In this paper, we propose a wireless moisture sensor based on the backscatter characteristic of the micro-strip antenna, which works in the far field without a battery.
The power is supplied by an electromagnetic wave from a transmitter to the sensor.

\section{Principle of Sensing}

The proposed sensor consists of a micro-strip antenna and a load resistance. Figures 1(a) and 1(b) show the photograph of the sensors, which were designed for the same characteristics. (a) A 1.6-mm-thick rigid printed circuit board made of FR4 (glass epoxy: $\varepsilon_{r}=4.6$ ) and (b) a 0.025 -mm-thick flexible printed circuit board made of cover-lay-coated PI (polyimide: $\left.\varepsilon_{r}=3.6\right)$ were used as the substrates. The flexible printed circuit board was in the form of film and easy to handle, but an FR4 printed circuit board was used for the present experiments, because PI was somewhat hygroscopic and was not suitable for repeated use. The load resistance $\left(R_{L}\right)$ of $50 \mathrm{ohm}$ was soldered in the center of the print circuit boards. The sensitivity of the water detection depends on the shape of the micro-strip antenna. Further study is needed to find a more highly sensitive antenna shape.

Figure 2 shows the measured frequency response of the $\left|S_{11}\right|$ parameter for the sensor, that is, the reflection coefficient of the sensor terminated by the resistance load of $50 \mathrm{ohm}$. The measurement was carried out with the network analyzer connected to the sensor by the coaxial cable. The cyan line and magenta line show $\left|S_{11}\right|$ characteristics for 


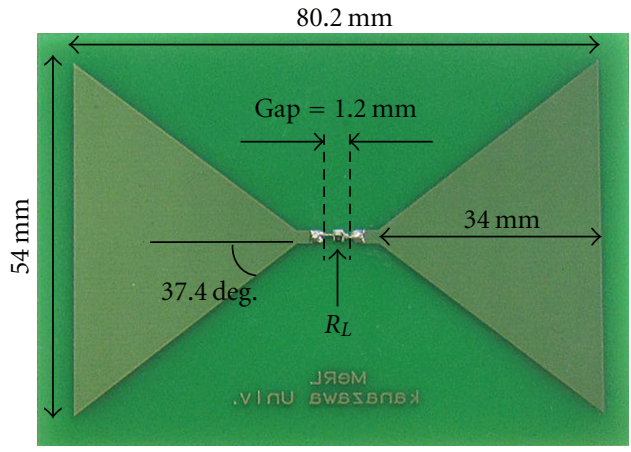

(a)

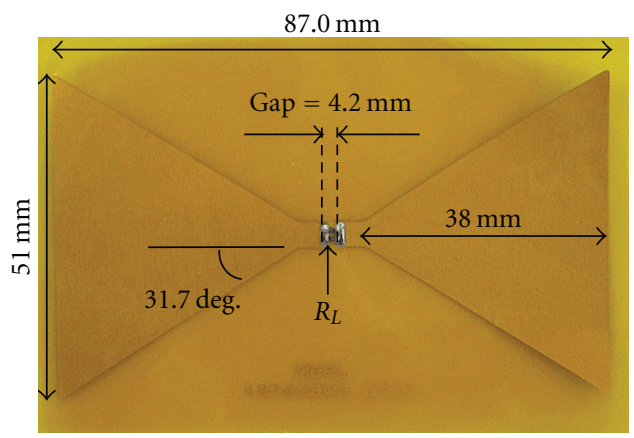

(b)

FIGURe 1: Photographs of sensors on (a) rigid printed circuit board made of glass epoxy and (b) flexible printed circuit board made of polyimide.

the sensor unwatered and exposed to the moisture, respectively. The distilled water was added on the cleaning tissue (Nippon Paper Crecia Co. and Kimberly-Clark Corporation, KimWipes) that was stuck on the sensor. The volume of the water was $500 \mu \mathrm{L}$, and the weight percent in the tissue was $77.0 \%$. However, the moisture in the paper was not given uniformly. The dip of the $\left|S_{11}\right|$ shows the impedance matching between the antenna and resistance load. In the matching condition, the electromagnetic power is absorbed by the sensor efficiently and consumed by the resistance load. On the other hand, in the frequency range where the $\left|S_{11}\right|$ is near zero, the electromagnetic power is not received by the sensor but is scattered to the surrounding space. The influence of the moisture is observed as the shift to the lowfrequency side or the long wavelength side, which is a known effect of shortening of the wavelength caused by a high permittivity dielectric such as water [8]. In the $2.5 \mathrm{GHz}-$ $3 \mathrm{GHz}$ band, the dip of the $\left|S_{11}\right|$ curve is slightly shifted to the high frequency side by the exposure to the moisture, because the $\left|S_{11}\right|$ is significantly influenced by the dielectric loss caused by the water [9]. The moisture of the sensor surface is monitored by measuring the backscattered power ratio at two appropriate frequencies. In this work, $0.954 \mathrm{GHz}$ and $2.45 \mathrm{GHz}$ were used to measure the backscattered power, because these frequency bands are available for the radiofrequency identification (RFID) system in Japan. However, the reassignment of the frequency band for the UHF RFID

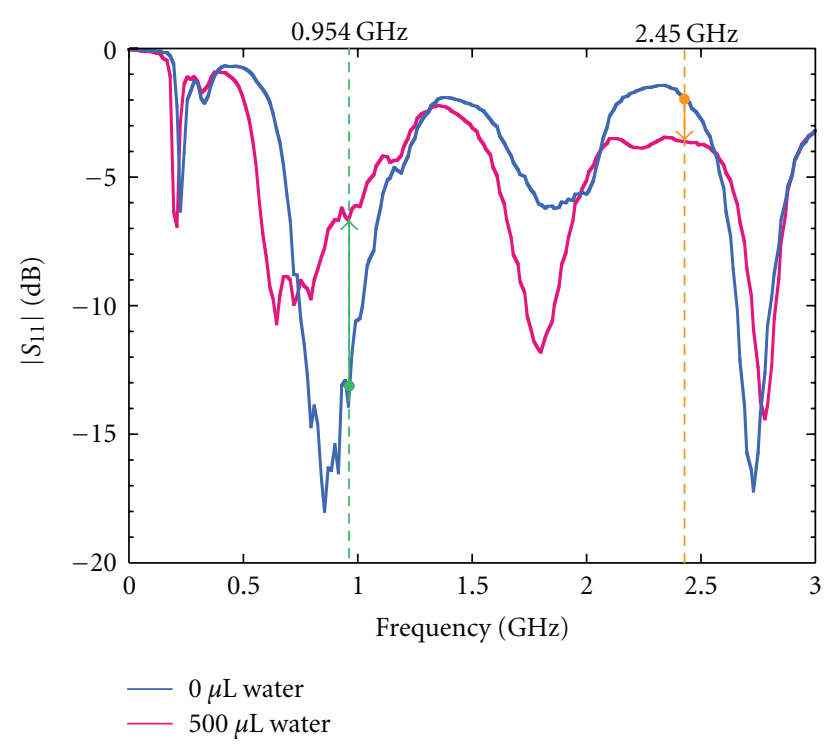

Figure 2: Measured frequency response of $\left|S_{11}\right|$ parameter for sensor. Cyan line and magenta line show characteristics for sensors that were unwatered and exposed to moisture, respectively.

system in Japan is planned to align it with the global standard.

The reflected power at $0.954 \mathrm{GHz}$ is increased by the moisture, while that of $2.45 \mathrm{GHz}$ is decreased as seen in Figures 2 and 3. In this case, the antenna has to be designed to have no less than two impedance-matching frequencies, which are arranged in the frequency bands less than $0.954 \mathrm{GHz}$ and more than $2.45 \mathrm{GHz}$. The sensitivity to the change in water volume tends to be saturated for the water contents over $800 \mu \mathrm{L}$. The water volume of $800 \mu \mathrm{L}$ is equivalent to the average water layer thickness of $0.16 \mathrm{~mm}$ on the antenna. It is speculated that the sensitivity saturation is caused by the thick water layer absorbing the electromagnetic wave. Therefore, this sensor cannot be used under the environment that there is too much volume of the water but is suitable to detect the moisture or to measure the small water content of materials from the outside.

In most applications, the detected water is not distilled water but conductive water. The frequency response of the sensor antenna was measured to the $2.0 \mathrm{wt} . \%-\mathrm{NaCl}$ solution. However, no significant change could be observed for the $\mathrm{NaCl}$ addition. The conductivity of the saline solution was estimated at $33 \mathrm{mS} / \mathrm{cm}$. The concentration of the saline solution may be too low to change the antenna characteristics. The electromagnetic field simulation for the microstrip antenna on the conductive dielectric substrate predicted the slight shift of the impedance-matching frequency to the high-frequency side and the distortion of the overall frequency response curve. The dependence of the antenna characteristics on the concentration of the solution should be investigated in accordance with the target application. 


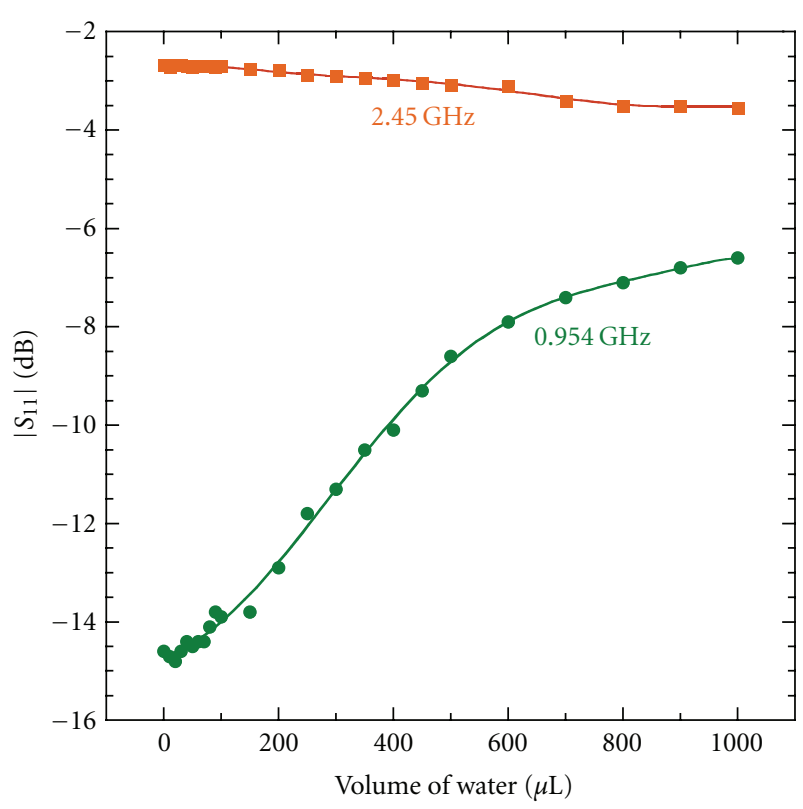

Figure 3: Water-volume dependence of $\left|S_{11}\right|$ at $2.45 \mathrm{GHz}$ and $0.954 \mathrm{GHz}$.

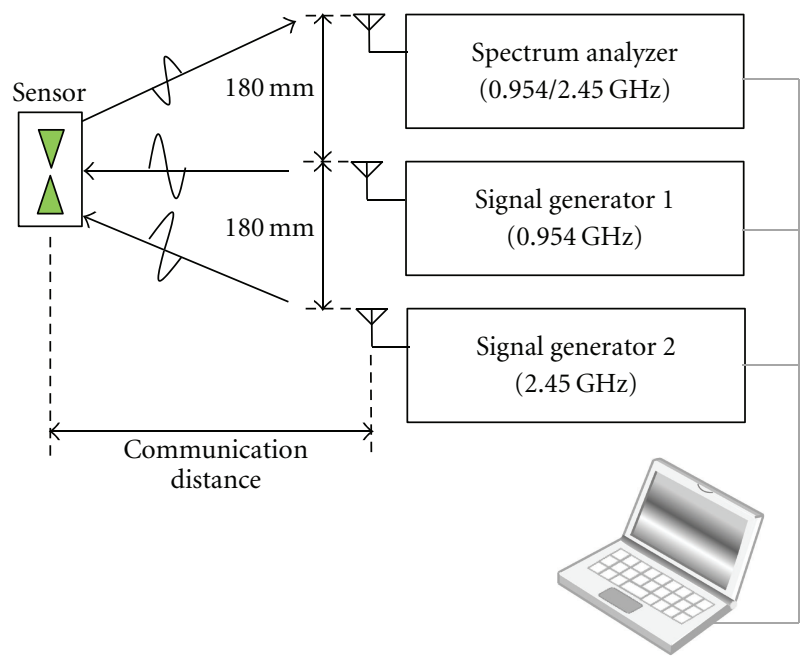

FIGURE 4: Block diagram of measurement system.

\section{Measurement System}

Figure 4 shows the block diagram of the present measurement system. This system consists of two signal generators used as transmitters (Rohde and Schwarz SVBM100A) and a spectrum analyzer used as a receiver (Tektronix RSA3408B). In the practical system, the signal generators, and the spectrum analyzer can be replaced with a $0.954 \mathrm{GHz}$ oscillator, $2.45 \mathrm{GHz}$ oscillator, and a received signal strength indication (RSSI) circuit. The sensor placed in the communication range scatters the electromagnetic wave transmitted from the signal generators and the spectrum analyzer detects the variation of the electromagnetic power backscattered by the sensor. The power of the backscattered electromagnetic wave is much smaller than that of the directly propagated wave

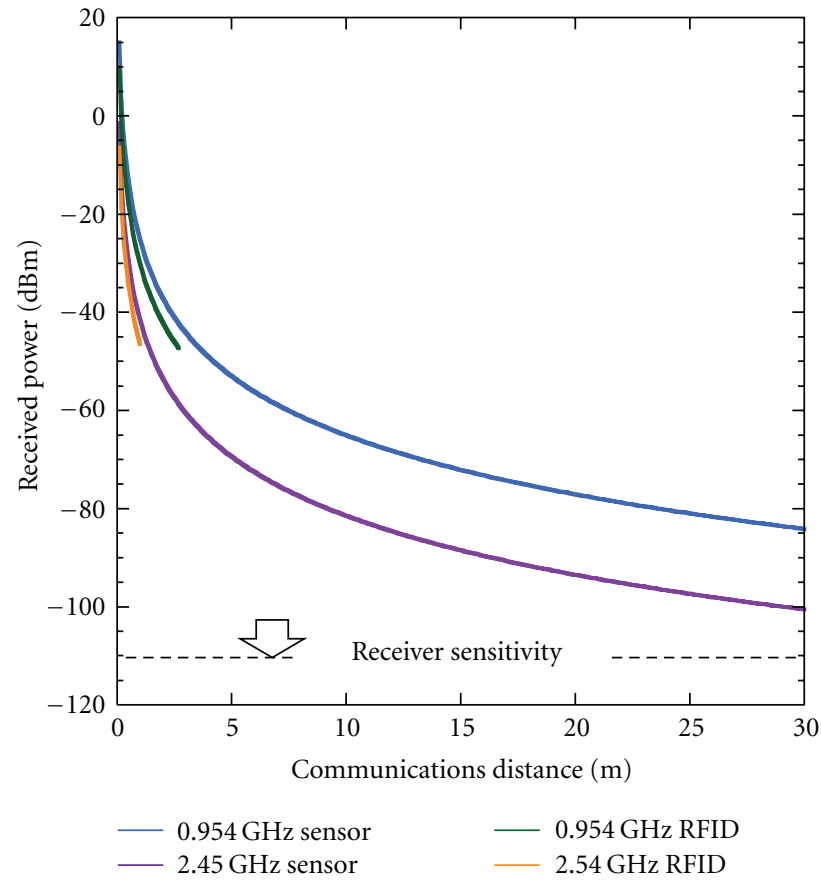

FIGURE 5: Calculated received power of electromagnetic wave backscattered by sensor.

TABle 1: Parameters to calculate communication-distance dependence of received power. $\left|S_{11}\right|$ of real sensor will range from negative infinity to 0 by $\mathrm{dB}$ unit.

\begin{tabular}{lcccc}
\hline$P_{\mathrm{TX}}(\mathrm{dBm})$ & $G_{S}(\mathrm{~dB})$ & $G_{M}(\mathrm{dBi})$ & $L_{P}(\mathrm{~dB})$ & $\left|\mathbf{S}_{11}\right|(\mathrm{dB})$ \\
\hline+30 & 0.0 & +6.0 & -3.0 & 0.0 \\
\hline
\end{tabular}

from the transmitters. The time variation of the power of directly propagated wave disturbs the measurement of the backscattered power. Therefore, the time variation of the propagation environment of the electromagnetic wave in the communication range should be avoided.

The received power (PRX) of the electromagnetic wave backscattered by the sensor was calculated by using (1) on the basis of the Friis transmission formula [10]

$$
P_{\mathrm{RX}}=\left(\frac{\lambda}{4 \pi d}\right)^{4} G_{S}^{2} G_{M}^{2} L_{P}\left|S_{11}\right|^{2} P_{\mathrm{TX}},
$$

where $P_{\mathrm{TX}}$ is a transmitted power from the transmitter, $\lambda$ is a wavelength of electromagnetic wave, $d$ is a communication distance, $G_{S}$ is an antenna gain of the sensor, $G_{M}$ is an antenna gain of the transmitter and receiver, and $L_{P}$ is a conversion loss from circular polarized wave to linearly polarized wave. Figure 5 shows the calculated received power of the electromagnetic wave backscattered by the sensor. The parameters for the calculation in Table 1 are taken from the Association of Radio Industries and Business STD-T89 Standard for RFID in Japan.

The maximum communication distance between the transmitter/receiver and the sensor depends on the receiver sensitivity. The minimum input signal level of the receiver in a wireless communication system is usually less than 


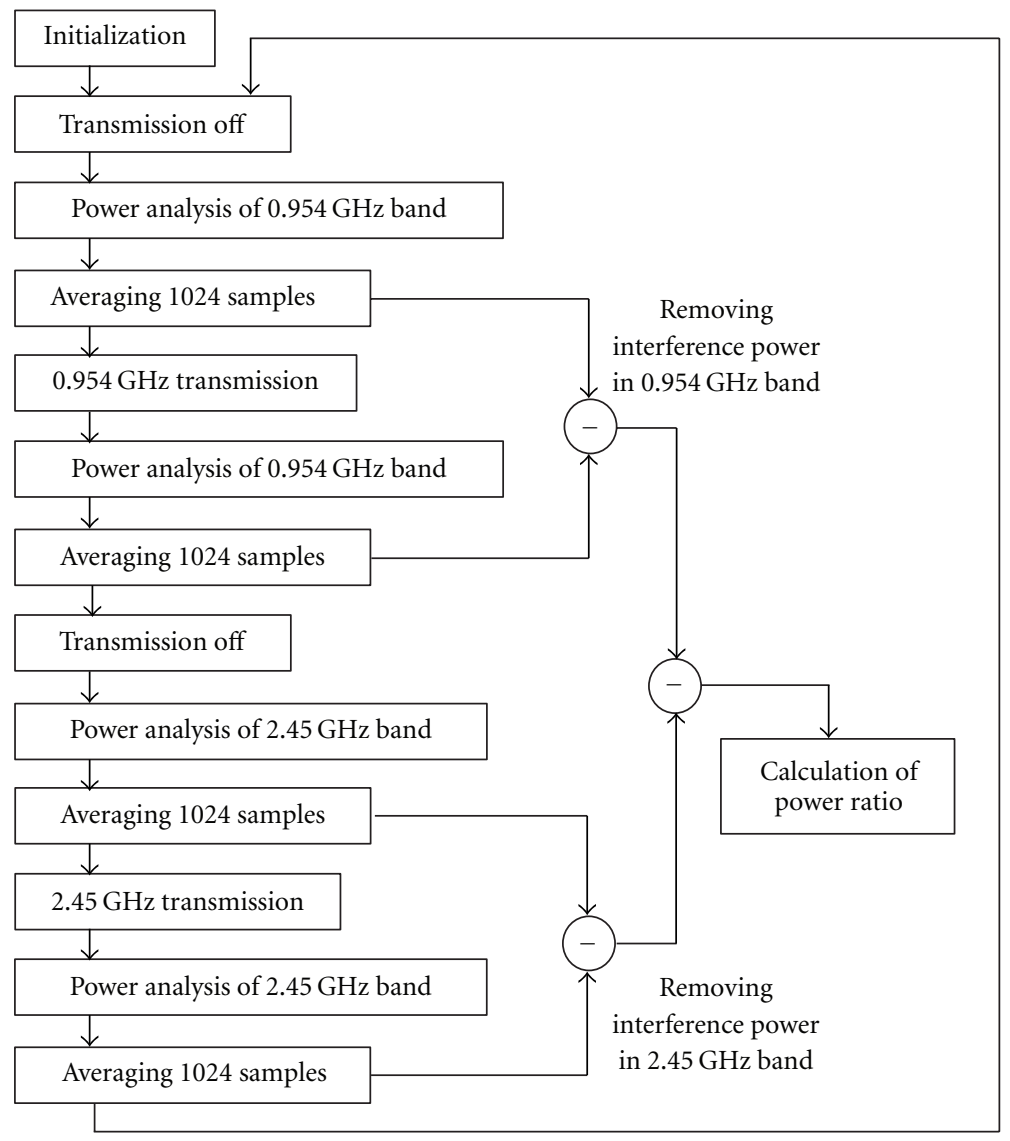

FIGURE 6: Flow chart of wireless moisture measurement.

$-110 \mathrm{dBm}$. Therefore, the maximum communication distance is expected to be several tens of meters. The communication distance of RFID is also plotted in Figure 5. The additional losses $\left(L_{X}\right)$ occur due to the impedance mismatch of the transponder circuit for the antenna and backscatter modulation in RFID systems. Furthermore, the maximum communication distance of the passive RFID system ( $\left.d_{\text {max _RFID }}\right)$ strongly depends on the threshold power of the RFID tag [11], which is required to operate the transponder circuit, as shown in

$$
d_{\text {max _RFID }}=\frac{\lambda}{4 \pi} \sqrt{G_{S} G_{M} L_{P} L_{X} \frac{P_{\mathrm{TX}}}{P_{C}}},
$$

where $P_{C}$ is a threshold power of the RFID tag and $L_{X}$ is the additional losses in the RFID system. $L_{X}$ is usually about $-5 \mathrm{~dB}$, and $P_{C}$ depends on the circuitry of the transponder. The power consumption of the simple transponder is about $10 \mu \mathrm{W}(=0.01 \mathrm{dBm})$. In the case shown in Table $1, d_{\max \text { RFID }}$ for $0.954 \mathrm{GHz}$ and $2.45 \mathrm{GHz}$ are estimated at $2.73 \mathrm{~m}$ and $1.06 \mathrm{~m}$, respectively. The maximum communication distance of the proposed sensor system is not limited by the power consumption of the transponder circuit. Therefore, the proposed sensor system achieves a very long communication distance.

The flow chart of the wireless moisture measurement is shown in Figure 6. This flow chart was implemented with
LabView (National Instruments Co.). In this measurement procedure, the interferences by other wireless communication systems were removed, and then, the ratio of the power at $2.45 \mathrm{GHz}$ against the power at $0.954 \mathrm{GHz}$ was computed.

In the initialization process, the transmitted powers at $0.954 \mathrm{GHz}$ and $2.45 \mathrm{GHz}$ are adjusted to be lower than the maximum input power level of the receiver to prevent the receiver from overloading. The transmitted power that is as high as possible in the range that does not conflict with the radio law is suitable for performing high sensitivity measurements. Then, the transmitted power ratio between $0.954 \mathrm{GHz}$ and $2.45 \mathrm{GHz}$ is fine-tuned so that the received power ratio becomes near zero. Furthermore, the calibration process is required to measure the absolute volume of the water per sensor area. The calibration curve is given by measuring the reflected power ratio at $0.954 \mathrm{GHz}$ and $2.45 \mathrm{GHz}$ as a function of volume of the water on the sensor. In this work, the measurement was performed without any calibration to detect the relative change in the water wet.

\section{Measurement Results}

The trace of the temporal changes in the water volume is important for many practical purposes. The time domain measurement at the fixed frequencies is useful to detect the temporal changes in water volume on the sensor, because the frequency sweep of electromagnetic wave in free space 


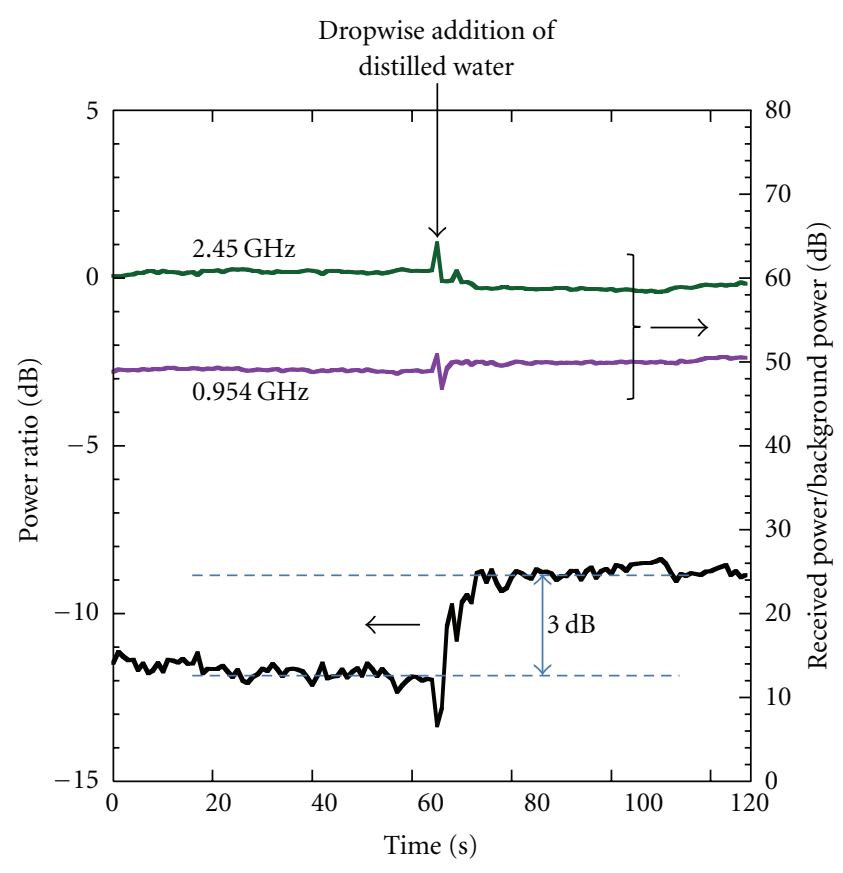

FIGURE 7: Transient response of received power and ratio of power at frequencies of $0.954 \mathrm{GHz}$ and $2.45 \mathrm{GHz}$. Transmitted powers were set to $-30 \mathrm{dBm}$ for $0.954 \mathrm{GHz}$ and $-10 \mathrm{dBm}$ for $2.45 \mathrm{GHz}$, respectively. Communication distance was $500 \mathrm{~mm}$.

cannot be used in compliance with the Radio Law, and it is difficult to design the transmission antenna with the uniform frequency response in the measurement frequency band. Therefore, the time domain measurements were performed in this work.

The transient responses of the received power at $0.954 \mathrm{GHz}$ and $2.45 \mathrm{GHz}$ were measured. The transmitted powers were set to $-30 \mathrm{dBm}$ for $0.954 \mathrm{GHz}$ and $-10 \mathrm{dBm}$ for $2.45 \mathrm{GHz}$, respectively. The communication distance was $500 \mathrm{~mm}$. These power levels ensure the communication distance of $3 \mathrm{~m}$, according to (1). Figure 7 shows the transient response of the received power measured by the spectrum analyzer and the ratio of the power at the frequency of $0.954 \mathrm{GHz}$ and $2.45 \mathrm{GHz}$. The power is represented in the ratio against the background power in the frequency bandwidth of $10 \mathrm{kHz}$. The distilled water of $100 \mu \mathrm{L}$ was added on the cleaning tissue stuck on the sensor at $64 \mathrm{~s}$. The transient of the power ratio is observed for about $10 \mathrm{~s}$. This transient time is almost equal to the time it takes the water to infiltrate the paper tissue.

The power ratio as a function of volume of the water on the sensor was measured. The transmitted power and the communication distance were the same as those in the previous experiment. The distilled water was added on the cleaning tissue stuck on the sensor, and the power ratio was measured at the time of $10 \mathrm{~s}$ after the addition of the water. The measurement was repeated five times, and the average value and fluctuation of the measured power ratio are shown in Figure 8. The fluctuation of the measured power ratio dominantly depends on the time variation of the electromagnetic propagation environment; that is, the movement of the

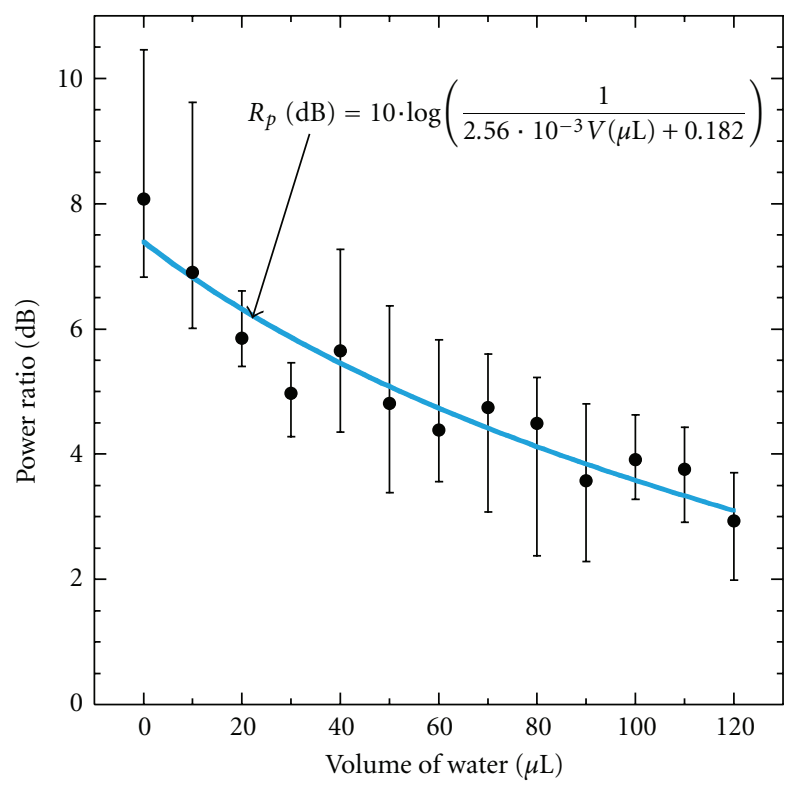

Figure 8: Power ratio as function of volume of water on sensor.

human body, the microsyringe, or beakers around the sensor disturb the electromagnetic propagation. The fluctuation of the power ratio can be rejected by time-averaging the measured reflection power several times. However, it was difficult to measure the water volume dependence of the power ratio in the high moisture region, because the power ratio tends to be saturated in the high moisture region more than $120 \mu \mathrm{l}$ (19.6\% in the tissue).

The power backscattered by the sensor is inversely proportional to the average permittivity of the sensor substrate and the wet tissue with water if only the effect of the wavelength being shortened by the high permittivity dielectric is considered. Therefore, it was expected that the function of $10 \log (1 /$ Volume $)$ could be fitted. Two fitting parameters, which are associated with dielectric constants of water and the substrate of the antenna, were optimized to fit the measurement result. The fitting curve obtained by the leastsquares method is put down with the measurement results in Figure 8.

\section{Conclusion}

A wireless moisture sensor has been developed on the basis of the backscatter characteristic of the micro-strip antenna, which works in the far field without a battery. The power is supplied by an electromagnetic wave from a transmitter to the sensor. The dropwise addition of the distilled water on the cleaning tissue is clearly detected by measuring of the backscattered power at the frequencies of $0.954 \mathrm{GHz}$ and $2.45 \mathrm{GHz}$. The ratio of the backscattered power in these frequency bands can be used as an index to measure moisture.

\section{Acknowledgments}

This work was supported by Grant-in-Aid for Scientific Research (C) (20510116), Grant-in-Aid for Exploratory Research 
(23651136) of Japan Society for the Promotion of Science (JSPS), and Adaptable and Seamless Technology Transfer Program through Target-driven R\&D (AS2121327A) of Japan Science and Technology Agency (JST).

\section{References}

[1] A. W. Kraszewski, Microwave Aquametry, IEEE Press, Piscataway, NJ, USA, 1996.

[2] R. Cardell-Oliver, M. Kranz, K. Smettem, and K. Mayer, "A reactive soil moisture sensor network: design and field evaluation," International Journal of Distributed Sensor Networks, vol. 1, pp. 149-162, 2005.

[3] K. Khalid, M. M. Ghretli, Z. Abbas, and I. V. Grozescu, "Development of planar microwave moisture sensors for hevea rubber latex and oil palm fruits," in Proceedings of the International RF and Microwave Conference (RFM '06), pp. 10-15, September 2006.

[4] M. N. Alam, R. H. Bhuiyan, R. A. Dougal, and M. Ali, "Concrete moisture content measurement using interdigitated near-field sensors," IEEE Sensors Journal, vol. 10, no. 7, pp. 1243-1248, 2010.

[5] G. C. Topp, J. L. Davis, and A. P. Annan, "Electromagnetic determination of soil water content using TDR: I. Applications to wetting fronts and steep gradients," Soil Science Society of America Journal, vol. 46, no. 4, pp. 672-678, 1982.

[6] M. P. Abegaonkar, R. N. Karekar, and R. C. Aiyer, "A microwave microstrip ring resonator as a moisture sensor for biomaterials: application to wheat grains," Measurement Science and Technology, vol. 10, no. 3, pp. 195-200, 1999.

[7] H. Xing, J. Li, R. Liu, E. Oshinski, and R. Rogers, "2.4 GHz on-board parallel plate soil moisture sensor system," in Proceedings of the Sensors for Industry Conference (Sicon '05), pp. 35-38, February 2005.

[8] D. M. Dobkin and S. M. Weigand, "Environmental effects on RFID tag antennas," in Proceedings of the IEEE MTT-S International Microwave Symposium Digest, p. 4, June 2005.

[9] J. B. Hasted, Aqueous Dielectrics, Chapman and Hall, London, UK, 1973.

[10] H. T. Friis, "A note on a simple transmission formula," Proceedings of the Institute of Radio Engineers, vol. 34, no. 5, pp. 254-256, 1946.

[11] P. V. Nikitin, K. V.S. Rao, S. F. Lam, V. Pillai, R. Martinez, and H. Heinrich, "Power reflection coefficient analysis for complex impedances in RFID tag design," IEEE Transactions on Microwave Theory and Techniques, vol. 53, no. 9, pp. 27212725, 2005. 

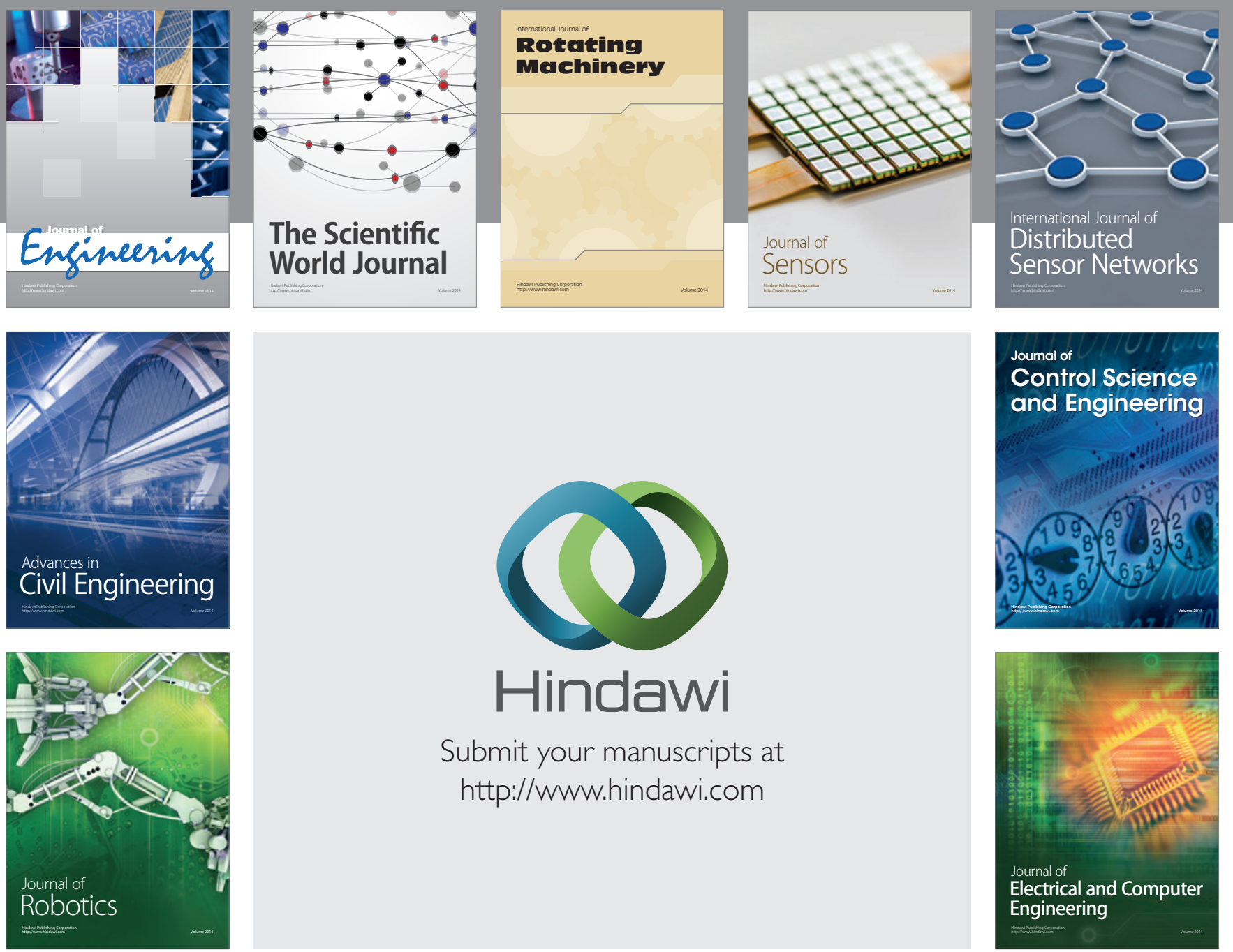

Submit your manuscripts at

http://www.hindawi.com
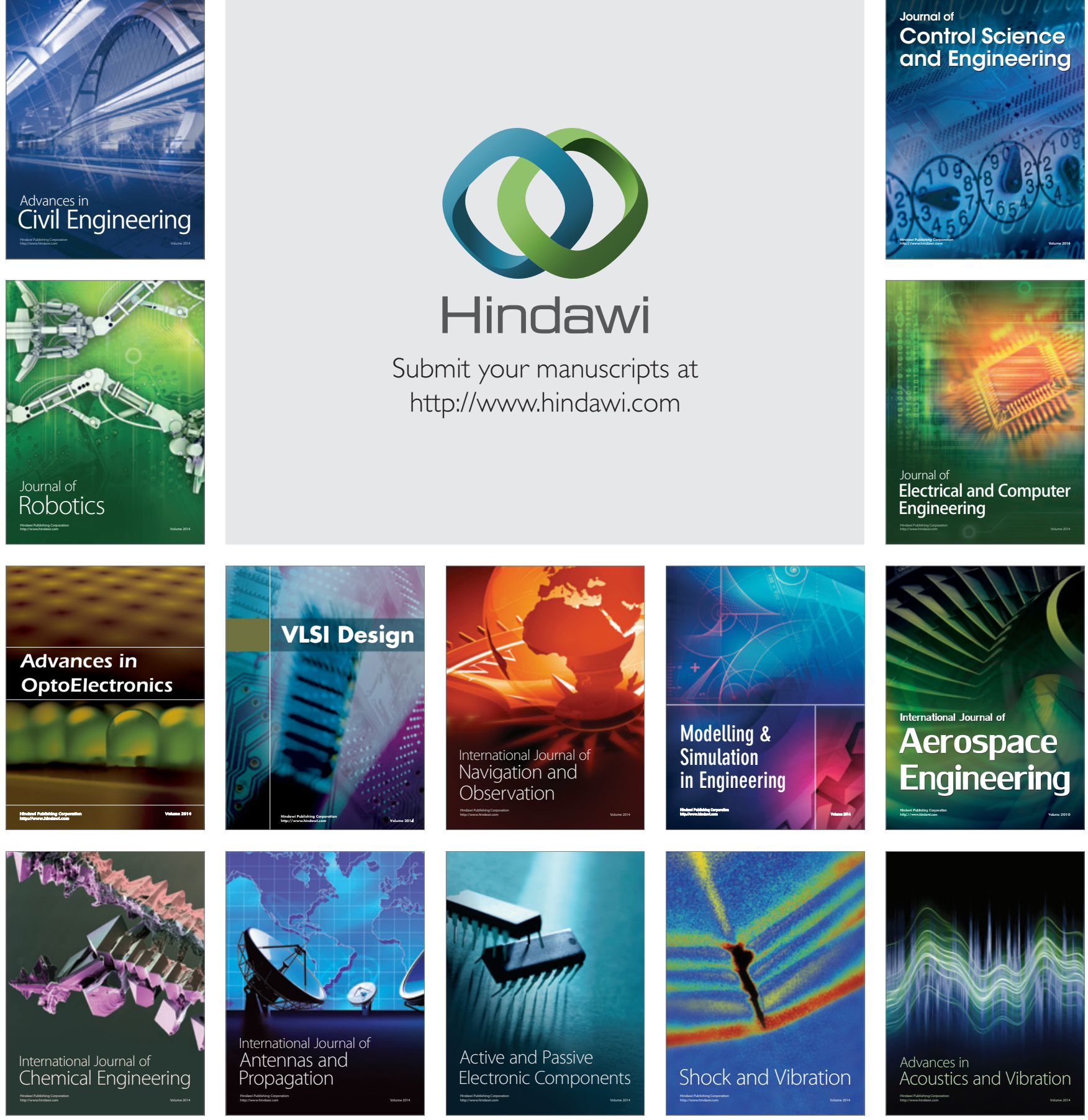